\title{
Usefulness of Polyherbal Unani Formulation for Cervical Ripening and Induction of Labour: A Uncontrolled Study
}

Arshiya Sultana ${ }^{1 *}$, Mazherunnisa Begum ${ }^{1}$, Shahzadi Sultana ${ }^{2}$ and Kumari Asma ${ }^{1}$

${ }^{1}$ Department of Obstetrics and Gynecology, National Institute of Unani Medicine, PG Institute of Research, Bangalore, Karnataka, India ${ }^{2}$ Department of Obstetrics and Gynecology, Govt Nizamia Tibbi College, Hyderabad, India

\begin{abstract}
Objectives: To evaluate the efficacy of polyherbal Unani formulation for cervical ripening and induction of labour

Material and Methods: A prospective, study was conducted in Govt. Nizamia Tibbia Hospital, Hyderabad. Pregnant women $(n=38)$ with gestation age of 38-42 weeks were recruited. A polyherbal Unani formulation powder of Cinnamomum tamala $3 \mathrm{~g}$, Gentiana lutea $1 \mathrm{~g}$, Pinus longifolia $1 \mathrm{~g}$ and Peganum harmala $5 \mathrm{~g}$ was administrated orally at an interval of 6 hours maximum of 4 doses and a pessary of Gossypium herbaceaum $2 \mathrm{~g}$, Euphorbia resinifera $0.5 \mathrm{~g}$ and borax $3 \mathrm{~g}$, was placed in the vagina at an interval of 6 hours, maximum of 4 doses. The main outcome measure was to observe mean induction to delivery interval and spontaneous vaginal delivery. The secondary outcomes were to evaluate rate of induction failure, women given cerviprime or/and oxytocin, cesarean delivery, Apgar score and admission to the neonatal unit.
\end{abstract}

Results: The mean induction to delivery interval was $12.3 \pm 4.7$ hours. Thirty two $(84.2 \%)$ pregnant women had spontaneous vaginal deliveries. Among induction failure (15.8\%), $7.8 \%$, delivered vaginally after instillation of cerviprime and/or oxytocin and $7.8 \%$ delivered by caesarean. Apgar scores at 1 and 5 minutes were 8.9 and 9.9 respectively. None of the babies were admitted in the neonatal unit.

Conclusion: The present study shows that the polyherbal Unani formulation was useful for reducing mean induction to delivery interval, and good perinatal outcome.

Keywords: Polyherbal unani formulation; Bishop score; Induction of Labour; Reduction of Induction and Delivery Interval

Introduction: Induction of labour is common in obstetric practice [1]. Induction of labour (IOL) means stimulation of contractions prior to the spontaneous onset of labour, with or without ruptured membranes. Labour induction will often commence with cervical ripening (a process that usually uses prostaglandins to soften and open the cervix), when the cervix is closed and uneffaced [2]. Induction of labour is required in $16 \%$ of deliveries [3]. The induction rate in the United States has more than doubled from $9.5 \%$ of all deliveries in 1990 to $22.5 \%$ in 2006 [4]. According to the most current studies, the rate varies from 9.5 to 33.7 percent of all pregnancies annually. Uterine contractions are initiated by medical or surgical means before the onset of spontaneous labour [1].

The World Health Organization (WHO) recommends induction should be performed with a clear medical indication and when expected benefits outweigh potential harms [5]. An ideal method of induction of labour (IOL) should combine both factors safety of mother and foetus, and convenience for the patient and the medical staff. Success of IOL is influenced by a combination of events existing prior to induction of labour, such as Braxton Hicks contractions, ratio of oestrogen and progesterone, prostaglandin, and the state of cervical collagen matrix (i.e., Bishop score) [6]. The oxytocic agents permitted for use in obstetrics to induce or augment labour or control postpartum bleeding are: oxytocin, prostaglandin E2, prostaglandin F2a, and ergometrine. However, these drugs causes uterine hyperstimulation in sufficiently high doses and use of ergometrine is restricted to the $3^{\text {rd }}$ stage of labour. The potential toxicity of these agents is well known and they are only administered by trained medical staff.

Labour induction in the presence of an unfavourable cervix is often prolonged, tiresome and can lead to induction failure [6]. The failure rate with an unfavourable cervix ranges from 25 to $50 \%$
[7]. Consequently, before a regimen is chosen, cervical ripening or preparedness for induction should be evaluated by calculating a Bishop score. When the Bishop score is less than 6 , it is recommended that a cervical ripening agent be used before labour induction [1]

The use of complementary therapies is increasing and some women look to complementary therapies during pregnancy and childbirth to be used alongside conventional medical practice [8]. Nonpharmacologic approaches to cervical ripening and labour induction have included herbal compounds, castor oil, hot baths, enemas, sexual intercourse, breast stimulation, acupuncture, acupressure, transcutaneous nerve stimulation, and mechanical and surgical modalities [1]. Herbal plants have been used as domestic medicine for child birth for decades and are well recognized from the ancient ages, which are now turned as medicinal plants [9]. Nowadays researchers are trying to develop different drugs with therapeutic uses from plant extracts. Researchers find that medicinal plants and their individual constituents act in similar fashion as the modern drugs and sometime better without the dreaded side effects [10]

According to Unani physicians, induction is successful when induced at term or post term. As uterine oxytocin receptors are

*Corresponding author: Dr. Arshiya Sultana, Assistant Professor, Department of Obstetrics and Gynecology, National Institute of Unani Medicine, PG Institute of Research, Bangalore, Karnataka, India, Tel: 09740915912; E-mail: drarshiya@ yahoo.com, mailto:drasnium@gmail.com

Received December 15, 2014; Accepted January 16, 2015; Published February 10, 2015

Citation: Sultana A, Begum M, Sultana S, Asma K (2015) Usefulness of Polyherbal Unani Formulation for Cervical Ripening and Induction of Labour: A Uncontrolled Study. Altern Integ Med 4: 184. doi:10.4172/2327-5162.1000184

Copyright: $\odot 2015$ Sultana A, et al. This is an open-access article distributed unde the terms of the Creative Commons Attribution License, which permits unrestricted use, distribution, and reproduction in any medium, provided the original author and source are credited. 
increased during this period and at this time foetus is fully developed to be able to undergo required movements necessary for the birth of the foetus [11]. They also mentioned that near term, when labour starts there will be pain in the abdomen and the cervical os becomes swollen, soft and moist [12]. Medicines having emmenagogue/ oxytocics property are usually helpful in inducing and augmenting the labour process, which helps in the expulsion of foetus and placenta [11] e.g., sudaab (Ruta graveolens), sheetraj hindi (Plumbago zeylanicum), Sheetraj hindi (Plumbago zeylanicum), chirchita (Achyranthas aspera), darchini (Cinnamomum zeylanicum), Cinnamomum tamala (taj), Gentiana lutea (juntiana), Pinus longifolia (behroza e khush musaffi), Peganum harmala (ispand,) Gossypium herbaceaum (beeqe kapas), Euphorbia resinifera (ferfyun) and borax are good medicine for easing labour mentioned in classical Unani texts [13]. Hence, the aim of this study is to evaluate the efficacy of polyherbal formulations in cervical ripening and induction of labour.

\section{Material and Methods}

\section{Study design and place of study}

This was a single centre, prospective, uncontrolled study with convenience sampling was conducted with pregnant women between March 2003 and February 2006 at Govt. Nizamia Tibbia College, Hyderabad. The protocol was approved by the Institute and NTR University of Health Sciences.

\section{Participants}

The inclusion criteria were singleton viable uncomplicated pregnancy with 38-42 weeks of gestation, cephalic presentation, reassuring foetal heart rate and Bishop score of less than or equal to 6 . Women without any foetal and maternal complications confirmed by clinical examination, antenatal routine blood profile, ultrasonography, and normal biophysical profile (BPP) (8-10) were included. Exclusion criteria were multigravida with previous scar on the uterus, documented fetal anomalies, parity more than 6 , multiple gestation, hypertension in gestation, cephalopelvic disproportion, intra uterine growth retardation, placenta praevia, diabetes and significant maternal cardiac, renal or hepatic diseases complicating pregnancy.

\section{Procedure}

All eligible pregnant women were invited to participate, and after obtaining the informed written consent demographic profile, obstetrical, family, and past history was noted. The labouratory investigations such as haemoglobin percentage, blood group and $\mathrm{Rh}$ typing, random blood sugar, HIV, HbsAg, VDRL, and urine routine were carried out. During the intrapartum period, the latent period, progress in Bishop Score, mode of delivery, induction to delivery interval, $3^{\text {rd }}$ stage blood loss, and fetomaternal outcome were also recorded. Clinical monitoring and progress of labour was plotted on the partograph. Dose repetition was stopped if women had developed any complications like hyperstimulation, tachysystole or hypersystole. When women did not achieve the active phase even after receiving the maximum dose of the trial drugs, induction was considered to have failed and other measures were undertaken such as artificial rupture of membranes, cervical ripening with cerviprime or/and oxytocin was implemented after 36 hours of initial induction with trial drugs.

\section{Assessment tools}

\section{Bishop score}

To assess cervical status, the modified Bishop score was used. The scoring system used 5 determinants (dilatation, effacement, station, position, and consistency) that attributed a value of 0 to 2 (for a maximum score of 10) (Table 1). A favourable pre-induction Bishop score of $>6$ was predictive of a successful vaginal delivery [1].

\section{Guidelines}

The practical guidelines for administration of trial medication were as follows: Fetal heart rate (FHR) and uterine activity were constantly monitored throughout labour induction; Artificial rupture of the membrane was performed with physician judgment if rupture of membranes had not occurred with a Bishop's score of 9 or above; Induction failure was defined as not entering into the active phase after 24 hours of treatment with a maximal cumulative dosage; After induction failure with polyherbal formulation or other methods or a prolonged active phase, cesarean delivery was considered [14].

Induction was considered successful with more favourable cervix (Bishop score greater than or equal to 7) or adequate uterine activity or entering active labour. Adequate uterine activity were defined as occurring every 2-3 minutes and lasting 60-90 seconds, with an intrauterine pressure $50-60 \mathrm{~mm} \mathrm{Hg}$. Whereas, the presence of at least six contractions in 10 minutes over at least two 10 -minute windows was defined as tachysystole. A single contraction lasting more than 2 minutes was defined as hypertonus. Tachysystole or hypertonus with non reassuring FHR changes was defined as hyperstimulation. Fetal heart rate changes considered to be non-reassuring were tachycardia, or reduced FHR variability, severe variable deceleration, prolonged deceleration or late deceleration, requiring intervention either by tocolytics or delivery.

\section{Intervention}

Selection of herbs was done on the basis of emmenagogue, oxytocics, antispasmodic, and resolvent properties after thorough review of the Unani literature, and conventional methods for induction of labour. Information about the herbs, their action, side effects, chemical constituents, pharmacology was obtained through review of ancient and modern literature. The herbs were described to be safe for mother and foetus and in day to day practice they were observed beneficial for cervical priming and induction of labour, thus selected for confirmation of their effect on induction of labour.

\section{Method of preparation}

Trial crude herbs were purchased from authentic sources and properly identified by the chief pharmacist based on pharmacopoeial standard of Unani formulation. All ingredients were cleansed and grinded separately to make fine powder (safoof) and passed through mesh no.100, then equal proportion of each drug was mixed thoroughly and a finished powder was made. It was kept in cool, dry and dark place to keep it safe.

\section{Dosage and method of use}

A polyherbal Unani formulation powder containing Cinnamomum

\begin{tabular}{|c|c|c|c|}
\hline \multirow{2}{*}{ Factor } & \multicolumn{3}{|c|}{ Score } \\
\cline { 2 - 4 } & 0 & 1 & 1 \\
\hline Dilatation & 0 & $1-2$ & $3-4$ \\
\hline Effacement $\%$ & $0-30$ & $40-60$ & $60-70$ \\
\hline Length $(\mathrm{cm})$ & $>3$ & $1-3$ & $<1$ \\
\hline Consistency & Firm & Medium & Soft \\
\hline Position & Posterior & Mid & Anterior \\
\hline Station & Sp-3 or above & Sp-2 & Sp-1 or 0 \\
\hline
\end{tabular}


tamala (taj) leaves $3 \mathrm{~g}$, Gentiana lutea root (juntiana) $1 \mathrm{~g}$, Pinus longifolia resin (behroza e khush musaffi) $1 \mathrm{~g}$ and Peganum harmala seeds (ispand) $5 \mathrm{~g}$ was administrated orally at an interval of 6 hours maximum of 4 doses and a pessary of Gossypium herbaceum root (beeqe kapas) $2 \mathrm{~g}$, Euphorbia resinifera latex (ferfyun) $0.5 \mathrm{~g}$ and borax $3 \mathrm{~g}$, was placed in the vagina at an interval of 6 hours, maximum of 4 doses [13].

\section{Outcome}

The primary outcome was to evaluate efficacy were the interval from the first dose to vaginal delivery and the percentage of women who delivered infants vaginally within 12 hours and 24 hours of induction. The secondary outcome was to evaluate rate of induction failure, women given cerviprime or/andoxytocin, cesarean delivery and neonatal outcomes including lower Apgar score (less than 7 at 5 minutes), and admittance to the neonatal unit. Tachysystole, hypertonus, uterine hyperstimulation, and nonreassuring fetal heart rate were also observed.

\section{Data Analysis}

The results were analyzed statistically using Graph Pad Instat version 3.00 for window (Graph Pad Software, San Diego, Calif, USA) at completion of the study.

\section{Statistical analysis}

The descriptive statistical analysis has been carried out in the present study. Results on continuous measurements were presented on Mean \pm SD and categorical measurements were presented in number (\%).

\section{Results}

A total number of 68 pregnant women were interrogated during the study period. Among 68 women, fifteen were not willing to participate, three had oligohydramnios, two had intra uterine growth retardation, three had hypertension in pregnancy, two were twin pregnancy and five were post caesarean hence were excluded and remaining 38 pregnant women were included with convenience sampling.

\section{Baseline characteristics}

The mean age of pregnant women, parity and mean Bishop score are summarized in Table 2. The mean $\mathrm{Hb} \%$ and random blood sugar was $10.16 \pm 0.8$ and $93.2 \pm 9.9 \mathrm{mg} / \mathrm{dl}$ respectively. HIV, HBsAg and VDRL were negative in all pregnant women.

\section{Primary outcome}

The mean induction delivery interval was $12.3 \pm 4.7$ hours. There were significantly more women who delivered vaginally within 12 hours and 24 hours (Table 3 ). Thirty two $(84.2 \%)$ pregnant women had spontaneous vaginal deliveries in the present study (Table 4).

\section{Secondary outcome}

Induction failure was observed among $15.8 \%$ in which three (7.8\%) pregnant women had cesarean deliveries (Table 4). Foetal and neonatal characteristics are summarized in Table 5. Apgar scores at 1 and 5 minutes were 8.9 and 9.9 respectively. None of the babies were admitted in neonatal unit. There was no rise of blood pressure, pulse rate or, nonreassuring FHR, no uterine tachysystole or hyper stimulation observed and less amount of bleeding in 3rd stage of labour. No neonate required NICU care. No major side effects of the herbs were observed. Episiotomy was given in all primigravida and some multigravide, and wound healing was satisfactory. The rate of failed induction was higher for women with a very low Bishop score (0 to 2) in both nulliparous and parous women.

\section{Discussion}

There have hardly been any studies assessing the role of herbal medicine for induction of labour. This is first of its kind using the Unani system of medicine with the use of the above polyherbal formulation and therefore it is difficult to compare this study with previous studies that used the same system of medicine.

The present study shows that the polyherbal Unani formulation was helpful in inducing the labour at term and with post term uncomplicated pregnancies. The mean induction to delivery interval was $12.3 \pm 4.7$ hours and spontaneous vaginal delivery was seen in $84.2 \%$. The rate of failed induction was higher for women with a very low Bishop score ( 0 to 2 ) in both nulliparous and parous women. This finding is in accordance with previous studies [14].

None of the babies were admitted in neonatal unit. There was no rise of blood pressure, pulse rate or, nonreassuring foetal heart rate, no uterine tachysystole or hyperstimulation observed and less amount of bleeding in 3rd stage of labour. No neonate required NICU care.

The herbs used in this formulation are having emmenagogue, oxytocics, uterine stimulant, uterotonic, resolvent, emollient, and abortifacient properties $[13,15,16]$.

The methods of labour induction include nonpharmacologic methods, pharmacologic methods, complementary and alternative medicine methods [17]. In conventional medicine, oxytocin has been used for decades to induce or augment labour. Other effective methods include prostaglandins, such as misoprostol and dinoprostone, and mechanical methods that encompass stripping of membranes, artificial rupture of membranes, etc. [2]. The relationship of oxytocin (OT) and its receptor is very important in obtaining adequate uterine activity. The myometrium contains receptors that are specific to oxytocin, stimulate myometrial contraction and prostaglandin formation in the deciduas. Oxytocin receptors increase with advancing gestation, and uterine sensitivity to oxytocin increases rapidly in spontaneous labour [18]. OT induces contraction by elevating intracellular calcium [19]. Prostaglandins act on the cervix to enable ripening by a number of different mechanisms. Prostaglandins allow for an increase in

\begin{tabular}{|c|c|}
\hline Characteristics & No. Of pregnant women $(\mathbf{n}=\mathbf{3 8})$ \\
\hline Age $(\mathrm{y})$ & $26.44 \pm 3.47$ \\
\hline Parity & $12(31.5)$ \\
\hline Primi & $12(31.5)$ \\
\hline Gravida 2 & $11(28.9)$ \\
\hline Gravida 3 & $2(5.2)$ \\
\hline Gravida 4 & $2(5.2)$ \\
\hline Gravida 5 & $3.52 \pm 1.10$ \\
\hline Bishop score & \\
\hline
\end{tabular}

Data Presented: No (\%).

Table 2: Baseline characteristics of pregnant women.

\begin{tabular}{|c|c|c|}
\hline $\begin{array}{c}\text { Induction delivery } \\
\text { interval hours }\end{array}$ & No. of patient $(\mathbf{n = 3 8 )}$ & Mean \pm SD \\
\hline$\leq 12$ & $15(39.5)$ & $8.30 \pm 2.2$ \\
\hline$>12$ and $\leq 24$ & $17(44.7)$ & $15.86 \pm 3.3$ \\
\hline$>24$ & $6(15.8)$ & $29 \pm 4.7$ \\
\hline
\end{tabular}

Data Presented: No (\%).

Table 3: Induction to delivery interval. 


\begin{tabular}{|c|c|}
\hline $\begin{array}{c}\text { Mode of delivery } \\
\text { Spontaneous vaginal delivery with trial } \\
\text { medication }\end{array}$ & $\begin{array}{c}\text { No. of pregnant women } \\
(\mathbf{n = 3 8 )}\end{array}$ \\
\hline $\begin{array}{c}\text { Spontaneous vaginal delivery after cerviprime } \\
\text { or/and oxytocin }\end{array}$ & $34(84.2)$ \\
\hline Forceps delivery & $2(5.2)$ \\
\hline Cesearean section & $1(2.6)$ \\
\hline Fetal distress & $3(7.9)$ \\
\hline Nonprogress of labour & $1(2.6)$ \\
\hline
\end{tabular}

Data Presented: No (\%).

Table 4: Mode of delivery.

\begin{tabular}{|c|c|}
\hline Characteristics & No. of baby $\mathbf{( n = 3 8 )}$ \\
\hline Gestational age (weeks) & $40.16 \pm 0.7$ \\
\hline Apgar score & \\
\hline 1 min $\leq 7$ & $3(7.9)$ \\
\hline 5 min $\leq 7$ & 0 \\
\hline Status liquor & $36(94.7)$ \\
\hline Clear & $2(5.3)$ \\
\hline Meconium staining & $1(2.6)$ \\
\hline Cesearean section for fetal distress & 0 \\
\hline Nursery admission & 0 \\
\hline Perinatal mortality & $2.95 \pm 0.3$ \\
\hline Wt of baby & \\
\hline
\end{tabular}

Data Presented: No (\%) or Mean \pm SD.

Table 5: Fetal and neonatal characteristics.

intracellular calcium levels, causing contraction of myometrial muscle and relaxation of cervical smooth muscle that facilitates dilation [20].

Traditional medicine relies on the use of certain herbal plants and other remedies for favorable effects during pregnancy, to induce labour, in the removal for retained placenta and management of postpartum bleeding. Most often the biological effects obtained by these remedies are because of biomolecules (small chemicals, peptides or proteins) that primarily act on the uterus. The nature of these actions may involve the modulation of uterine contractions at labour, resulting in either the stimulation ("uterotonic") or inhibition ("tocolytic") of myometrial muscle contractions [19].

The medicinal properties of many of plants have not yet been studied in molecular detail but it is clear that they may affect a number of different physiological targets and pathways in the female body. Uterotonic or oxytocic drugs are used to induce or augment labour and in the prevention or treatment of post-partum bleeding [20,21]

In the present study, polyherbal Unani formulation contains Cinnamomum tamala, Gentiana lutea Pinus longifolia, Peganum harmala, Gossypium herbaceum, Euphorbia resinifera latex and borax. Peganum harmala has antispasmodic and smooth muscle relaxant, [22] abortifacient $[15,16,23]$ properties, which helps in the dilatation of cervix and also helps to induce labour pain and normal contractions of uterus. Quinazoline alkaloids (e.g., vasicine and vasicinone) within $P$. harmala have been attributed to the abortifacient effect of this plant [23]. Abetic acid present in Pinus is pharmacologically proven for its spasmolytic activity, which might possibly helps in dilatation of cervix [24]. Pinus roxburghii is also pharmacologically proven for analgesic and anti-inflammatory activity [25].

Gossypium herbaceum has abortifacient and oxytocics property, Euphorbia resinifera is abortifacient, borax has abortifacient and antispasmodic effect [13,16]. Pinus longifolia resin and Gentiana lutea exhibited emmenagogue, and resolvent properties and helps in expulsion of foetus and placenta $[13,16]$. Emollient drugs help to soften the maternal tissue allowing passage for the delivering foetus. Niiho et al. In their gastroprotective study of Gentiana suggested that the therapeutic effects of Gentian root on gastric lesions were associated with enhanced mucosal defensive factors via the prostaglandin pathway in the cell membrane, and that secoiridoid glycosides contribute to this activity [26]. PGE1 are proven for its gastroprotective activity and it is also recognized for cervical ripening property. Therefore, probably gentiana was beneficial for induction of labour and cervical ripening as it acts on prostaglandin pathway. C. tamala also possess significant gastroprotective activity, probably due to its free radical scavenging activity [27]. C. tamala is also proven for its anti-inflammatory, analgesic, and antipyretic activities [28]. Euphorbia resinifera is proven for antimicrobial and antioxidant properties [29]. Hence, this polyherbal formulation was beneficial for cervical ripening and induction of labour without any adverse effects.

The strengths of this study are that it is first of its kind to study the Unani medicine, where polyherbal formulation has been used for cervical priming and induction of labour in unfavourable cervix. Patient compliance was good, all babies had good perinatal outcome with normal Apgar score, none of the patients had uterine hyperstimulaiton and other side effects.

Limitations of this study were the small sample size, sample size was not calculated and it was a non randomized uncontrolled study.

Further randomized controlled trials on a large sample size are recommended to prove its efficacy and safety to establish and confirm the results and to make it a patent herbal medicine.

\section{Conclusion}

Before implications for clinical practice can be made there is a need for well-designed randomized controlled trials to evaluate the role of polyherbal Unani formulation for cervical priming and to induce labour.

\section{References}

1. Tenore JL (2003) Methods for cervical ripening and induction of labor. Am Fam Physician 67: 2123-2128.

2. Cunningham FG, Leveno KJ, Bloom SL (2014) Williams Obstetrics. (24thedn). McGraw-Hill Education, New York, USA.

3. Calder AA (1997) Review of prostaglandin use in labour induction. Br J Obstet Gynaecol 104 Suppl 15: 2-7.

4. Laughon SK, Zhang J, Grewal J, Sundaram R, Beaver J, et al. (2012) Induction of labor in a contemporary obstetric cohort. Am J Obstet Gynecol 206: 486.

5. Goonewardene M, Rameez MFM, Kaluarachchi A (2011) WHO recommendations for induction of labour: $\mathrm{RHL}$ commentary. The WHO Reproductive Health Library; Geneva: World Health Organization.

6. Gupta N, Mishra SL, Shradha J (2006) A randomized clinical trial comparing misoprostol and dinoprostone for cervical ripening and labour induction. J Obstet Gynecol India 56: 149-151.

7. Brindley BA, Sokol RJ (1988) Induction and augmentation of labor: basis and methods for current practice. Obstet Gynecol Surv 43: 730-743.

8. Smith CA, Crow ther CA, Grant SJ (2013) Acupuncture for induction of labour Cochrane Database.

9. Chakraborty I, Ghosal S, Pradhan N (2014) Jussiaea repens (L) Acts as an Uterotonic agent - An in vitro study. Int J Pharm Sci Re. Res 27: 368-372.

10. Kennedy DA, Lupattelli A, Koren G, Nordeng H (2013) Herbal medicine use in pregnancy: results of a multinational study. BMC Complement Altern Med 13: 355. 
Citation: Sultana A, Begum M, Sultana S, Asma K (2015) Usefulness of Polyherbal Unani Formulation for Cervical Ripening and Induction of Labour: A Uncontrolled Study. Altern Integ Med 4: 184. doi:10.4172/2327-5162.1000184

Page 5 of 5

11. Ibn Sina (2010) Al Qanoon fit Tib. Central Council for Research in Unani Medicine, New Delhi.

12. Jurjani I. Zakheera Khawarzam Shahi. Central Council for Research in Unan Medicine, New Delhi, USA.

13. Ghani N (2001) Khazainul Advia. Idarae Kitabus Shifa, New Delhi, USA.

14. Xenakis EM, Piper JM, Conway DL, Langer O (1997) Induction of labor in the nineties: conquering the unfavorable cervix. Obstet Gynecol 90: 235-239.

15. Nadkarni KM (2009) Indian Materia Medica. Vol. II. Popular Prakashan Mumbai.

16. Chopra RN, Chopra IC, Varma BS (1998) Supplement to Glossary of Indian Medicinal Plants, National Institute of Science Communication, New Delhi, India.

17. Mozurkewich EL, Chilimigras JL, Berman DR, Perni UC, Romero VC, et al. (2011) Methods of induction of labour: a systematic review. BMC Pregnancy Childbirth 11: 84

18. Diven LC, Rochon ML, Gogle J, Eid S, Smulian JC, et al. (2012) Oxytocin discontinuation during active labor in women who undergo labor induction. Am J Obstet Gynecol 207: 471.

19. Gruber CW, O'Brien M (2011) Uterotonic plants and their bioactive constituents. Planta Med 77: 207-220.

20. Witter FR (2000) Prostaglandin E2 preparations for preinduction cervical ripening. Clin Obstet Gynecol 43: 469-474.

21. Chong YS, Su LL, Arulkumaran S (2004) Current strategies for the prevention of postpartum haemorrhage in the third stage of labour. Curr Opin Obstet Gynecol 16: 143-150
22. Moloudizargari M, Mikaili P, Aghajanshakeri S, Asghari MH, Shayegh J (2013) Pharmacological and therapeutic effects of Peganum harmala and its main alkaloids. Pharmacogn Rev 7: 199-212.

23. Shapira Z, Terkel J, Egozi Y, Nyska A, Friedman J (1989) Abortifacient potential for the epigeal parts of Peganum harmala. J Ethnopharmacol 27: 319-325.

24. Oechnowicz-Stepien W, Lamer-Zarawska E (1981). Searching for biologically active substances in Pine rosin. Herb Polon 27: 145-152.

25. Kaushik D, Kumar A, Kaushik P, Rana AC (2012) Analgesic and AntiInflammatory Activity of Pinus roxburghii Sarg. Adv Pharmacol Sci 2012 : 245431

26. Niiho Y , Yamazaki T, Nakajima Y (2006) Gastroprotective effects of bitter principles isolated from Gentian root and Swertia herb on experimentallyinduced gastric lesions in rats. Journal of Natural Medicines 60: 82-88.

27. Eswaran MB, Surendran S, Vijayakumar M, Ojha SK, Rawat AK, et al. (2010) Gastroprotective activity of Cinnamomum tamala leaves on experimental gastric ulcers in rats. J Ethnopharmacol 128: 537-540.

28. Thamizhselvam N, Soumya S, Sanjayakumar YR (2012) Anti-inflammatory analgesic and antipyretic activity of methanolic extract of Cinnamomum tamala (nees) in experimental animal models. International Journal of Bioassays (IJB) 01

29. Benmehdi H, Bounoua N, Amrouche A (2013) Phytochemical Study, antioxidant and antimicrobial activities of Euphorbia resinifera L. Int Res J Pharm 4: 44-50. 